\title{
Archives and Historical Libraries in Psychiatry
}

MArTin GuHa, Librarian, Institute of Psychiatry, London

Birley (1981) has quoted Whitehead as saying 'a science which hesitates to forget its founders is lost'. On the other hand, however, Hunter and MacAlpine (1963) noted that the historical study of psychiatry, unlike that of medicine, is inseparable from the appreciation of its current problems', and that 'just as it is the historical and biographical method which the psychiatrist adopts when faced with the problem of the individual patient, so the historical approach may be expected to throw light on the wider problems of psychiatry by laying bare their roots'. Certainly, since taking up appointment as librarian of the Institute of Psychiatry I have been surprised at the awareness of professional history shown by senior staff who I would have expected to be totally absorbed in day-to-day minutiae. A brief note in a specialized journal (Guha, 1983) elicited a considerable correspondence from psychiatric librarians who had noticed the same interest. It is, perhaps, unfortunate that historical resources in psychiatry are somewhat scattered, so that there is no one central archive or library to act as a focus for research in this area.

The Institute of Psychiatry possesses a collection of historic books, based originally on the library of Willi Mayer-Gross, with substantial additions left to the Institute by ex-members of staff, many of the books thus have the 'association value' of having formerly been the property of figures such as Conolly, Savage and Hack Tuke. Most recently work has started on adding to the collection some of the books left here by Sir Frederick Mott. These were, I gather, found by Sir Aubrey Lewis in the coal bunkers of the Maudsley Hospital and are in fairly atrocious condition. Fortunately the former Dean of the Institute had set up the Dean's Library Fund (to which contributions are always welcome!) and the income from this is now being made available to start restoration work.

The College Library is, itself, a noteworthy historical collection. Regrettably, the College did not obtain the Hunter-MacAlpine Library (Bulletin, January 1983, 7, 18), which is now housed at the University of Cambridge. Unfortunately, Cambridge have double-stacked the collection making access to half the stock impossible and have given 'a very low priority' to cataloguing it.

Outside the general libraries with large collections in psychiatry, such as the Wellcome and the RSM, there are a number of other collections of some historical interest. The Tavistock Joint Library has, for example, a considerable collection of older material. In a related field, the University of London Institute of Neurology, during its recent move, received a grant from the Lawley Foundation to shelve its historical books, so its unique collections are now relatively accessible. A number of hospitals are starting interesting archival and historical collections. Friern Hospital, for example, is developing a collection of archives and museum pieces, mainly relating to the history of Colney Hatch, but of considerable interest to the student of the history of psychiatry. The Institute of Psychiatry has an impressive collection of papers-manuscripts by Maudsley, Mapother, Mott, Mayer-Gross and, of course, Sir Aubrey Lewis, as well as memorabilia relating to the founding of the Institute, films of the opening of its new building, tape recordings of inaugural lectures, etc. All of these were, unfortunately, in very poor condition, and for the present I would discourage anyone from using them, for fear of making them worse. However, the Centre for Contemporary Medical Archives at the Wellcome Institute has offered to dust, clean, box and catalogue this material for us. When they have done so we are proposing to transfer it all to the archives at the Bethlem Royal Hospital, which is almost certainly the largest collection of this sort of material in this country.

The Centre for Contemporary Medical Archives is attempting to compile a catalogue of unpublished material in hospitals and other institutions, though even as 'professionals' they are, I gather, having considerable difficulty in tracking down obscure collections. Sokal and Rafail (1982), who produced a very useful guide to archive collections in the United States, noted the extreme difficulties faced by historians in tracing manuscripts in the UK, even when the author's institutional affiliations are known. Thus, as an extreme example, there is no way in which one could 'guess' that the Archbishop of Canterbury is the custodian of the records of the most thoroughly documented psychiatric case in history - that of George III (Bill, 1982). Once the work of the Centre for Contemporary Medical Archives is available it will make some historical research much easier-at the moment the standard guide to British archives (Foster and Sheppard, 1982) does not have any index entries at all under 'Psychiatry'. The few collections that they list are only indexed under the heading of 'Lunacy'.

\section{REFERENCES}

Bnw, E. G. W. (1982) Unexpected Collections at Lambeth Palace Library. University of London, Library Resources Coordinating Committee.

BiRLEY, J. L. T. (1981) Variations on a theme by Alfred North Whitehead. Bethlem and Maudsley Gazette, Summer issue, pp. 13-14.

FOSTER, J. \& ShEPPARd, J. (1982) British Archives. London: Macmillan.

GuHA, M. (1983) Historical resources in psychology and psychiatry. Medical Library Bulletin, January, pp. 5-6.

Hunter, R. \& MACAlPINE, I. (1963) Three Hundred Years of Psychiatry. Oxford University Press.

Sokal, M. M. \& RAfAII, P. A. (1982) A Guide to Manuscript Collections in the History of Psychology and Related Areas. New York: Kraus. 